\title{
Development and validation of a predictive model for estimating EGFR mutation probabilities in patients with non- squamous non-small cell lung cancer in New Zealand
}

Phyu Sin Aye ${ }^{1 *}$ (D), Sandar Tin Tin ${ }^{1}$, Mark James McKeage ${ }^{2,3}$, Prashannata Khwaounjoo ${ }^{2}$, Alana Cavadino ${ }^{1}$ and J. Mark Elwood ${ }^{1}$

\begin{abstract}
Background: Targeted treatment with Epidermal Growth Factor Receptor (EGFR) tyrosine kinase inhibitors (TKIs) is superior to systemic chemotherapy in non-small cell lung cancer (NSCLC) patients with EGFR gene mutations. Detection of EGFR mutations is a challenge in many patients due to the lack of suitable tumour specimens for molecular testing or for other reasons. EGFR mutations are more common in female, Asian and never smoking NSCLC patients.

Methods: Patients were from a population-based retrospective cohort of 3556 patients diagnosed with non-squamous non-small cell lung cancer in northern New Zealand between 1 Feb 2010 and 31 July 2017. A total of 1694 patients were tested for EGFR mutations, of which information on 1665 patients was available for model development and validation. A multivariable logistic regression model was developed based on 1176 tested patients, and validated in 489 tested patients. Among 1862 patients not tested for EGFR mutations, 129 patients were treated with EGFR-TKIs. Their EGFR mutation probabilities were calculated using the model, and their duration of benefit and overall survival from the start of EGFR-TKI were compared among the three predicted probability groups: $<0.2,0.2-0.6$, and $>0.6$.

Results: The model has three predictors: sex, ethnicity and smoking status, and is presented as a nomogram to calculate EGFR mutation probabilities. The model performed well in the validation group ( $A \cup C=0.75$ ). The probability cut-point of 0.2 corresponds $68 \%$ sensitivity and $78 \%$ specificity. The model predictions were related to outcome in a group of TKItreated patients with no biopsy testing available $(n=129)$; in subgroups with predicted probabilities of $<0.2,0.2-0.6$, and $>0.6$, median overall survival times from starting EGFR-TKI were 4.0, 5.5 and 18.3 months $(p=0.02)$; and median times remaining on EGFR-TKI treatment were 2.0, 4.2, and 14.0 months, respectively $(p<0.001)$.
\end{abstract}

Conclusion: Our model may assist clinical decision making for patients in whom tissue-based mutation testing is difficult or as a supplement to mutation testing.

Keywords: Non-small-cell lung carcinoma, Lung Cancer, Epidermal growth factor receptor, Mutation, Targeted therapy, Predictive models

\footnotetext{
* Correspondence: p.aye@auckland.ac.nz

${ }^{1}$ Epidemiology and Biostatistics, University of Auckland, B507, 22-30 Park Ave, Grafton, Auckland 1072, New Zealand

Full list of author information is available at the end of the article
}

(c) The Author(s). 2020 Open Access This article is licensed under a Creative Commons Attribution 4.0 International License, which permits use, sharing, adaptation, distribution and reproduction in any medium or format, as long as you give appropriate credit to the original author(s) and the source, provide a link to the Creative Commons licence, and indicate if changes were made. The images or other third party material in this article are included in the article's Creative Commons licence, unless indicated otherwise in a credit line to the material. If material is not included in the article's Creative Commons licence and your intended use is not permitted by statutory regulation or exceeds the permitted use, you will need to obtain permission directly from the copyright holder. To view a copy of this licence, visit http://creativecommons.org/licenses/by/4.0/ The Creative Commons Public Domain Dedication waiver (http://creativecommons.org/publicdomain/zero/1.0/) applies to the data made available in this article, unless otherwise stated in a credit line to the data. 


\section{Background}

Non-small cell lung cancer (NSCLC) comprises about $85 \%$ of all lung cancers. About $32.3 \%$ of NSCLC have mutation(s) of epidermal growth factor receptor (EGFR), ranging from $17.4 \%$ in Caucasian to $38.8 \%$ in Asian [1]. In addition to Asian ethnicity, EGFR mutations are well known for being more common among females and never smokers diagnosed with NSCLC $[1,2]$. EGFR gene mutations associated with NSCLC occur in the tyrosine kinase domain (exons 18 to 21) and lead to constitutive activation of the EGFR tyrosine kinase [3]. Some constitutively activated mutant EGFR proteins are sensitive to EGFR tyrosine kinase inhibitor (TKI) drugs, such as those encoded by EGFR genes with exon 19 deletion mutations or exon 21 L858R point mutation, whereas others are not, such as those encoded by EGFR genes with exon 20 insertion mutations [3]. When first introduced into clinical use, EGFR-TKIs were approved for use for any patient with NSCLC without molecular selection [4]. Since then, several randomised trials have shown that NSCLC patients with activating EGFR gene mutations are responsive to EGFR tyrosine kinase inhibitors (EGFR-TKI) such as gefitinib and erlotinib [5-12]. A meta-analysis including seven trials showed that EGFR-TKIs resulted in prolonged PFS overall and in all subgroups compared to chemotherapy, with greater benefits in patients with exon 19 deletions, no smoking history and in female patients [13].

Testing for EGFR mutations has become a critical first step in personalised treatment of lung cancer. For several years now, clinical practice guidelines have recommended EGFR mutation testing for most patients with NSCLC, for individualising treatment and selecting patients for EGFR-TKI therapy [14-16]. These guidelines recommend against using demographic or clinicopathological factors for selecting patients for testing [14-16]. Not testing all eligible patients risks missing some patients with EGFR mutations, who will miss out on treatment with EGFR-TKIs and their well-known clinical benefits. Not testing also risks treating some patients without EGFR mutations with EGFR-TKIs, who have little or no chance of benefit. EGFR mutation testing methodologies have improved in recent times, for example, in their analytical sensitivity for detecting low levels of mutations in tissue specimens and body fluids, such as blood plasma and pleural effusions [17].

Despite clinical guidelines and improved methodologies for testing, the potential of personalised treatment of lung cancer for improving patient outcomes has not yet been fully realised in the setting of routine care. Testing rates remain low in many parts of the world, fuelled by sample limitations, funding constraints and selective testing referral practices. For example, our recent systematic review of studies from throughout the globe that had evaluated the utilisation of EGFR mutation testing in the setting of routine care, found that less than one third of a total of over 50,000 patients from 18 eligible studies were tested for EGFR mutations [18]. So, the implementation of EGFR mutation testing into routine clinical practice appears to have been less successful than might have been expected. Further effort will be required beyond aspirational guidelines and new testing methods to increase testing rates and appropriate use of EGFR-TKIs. To do so, estimation of pretest probability of EGFR mutations from universally available demographic factors has been suggested as a potential adjunct to mutation testing [19].

EGFR-TKIs became available in New Zealand from October 2010 [20]. EGFR gene mutation testing has been recommended in New Zealand for all NSCLC patients, except those with confidently diagnosed squamous cell carcinoma, since May 2013 [20]. Soon after testing had commenced in New Zealand, we began a population-based cohort study of non-squamous NSCLC patients presenting in northern New Zealand, which is on-going. Previously we reported on the uptake and impact of EGFR mutation testing in 1857 cohort patients diagnosed up until April 2014 [20]; EGFR mutation retesting of a subgroup of 532 cohort patients [21]; the impact of incomplete uptake of testing on estimates of mutation prevalence in 2701 cohort patients diagnosed up until December 2015 [22], and screening for ALK gene rearrangements in 3130 cohort patients diagnosed up until July 2016 [23]. In this large population-based study, in northern New Zealand, only $3.7 \%$ of nonsquamous NSCLC patients were tested in 2010; this increased to $64.6 \%$ in 2014 and remained stable afterwards $[20,22]$. These suboptimal testing rates were explained by selective referral practices and the lack of suitable tumour specimens being available for testing [20, 22]. EGFR mutation testing of plasma (liquid biopsy) offers one solution $[24,25]$ but it is prone to false negative test results, and it is expensive and not readily available in New Zealand. Thus, a good estimate of EGFR mutation probabilities would assist clinical decision making for treatment with EGFR-TKIs for patients with no test result available.

In a literature review up to Aug 2019, we identified nine EGFR mutation prediction models [26-34] that had been validated in an independent dataset. However, those studies were based on limited numbers of patients, confined to non-Asian patient populations, or included predictors that are routinely unavailable such as certain radiological features. The validity of these models in the New Zealand context is unknown, and may be more limited as New Zealand has diverse ethnic groups including Māori and Pacific people. Thus, we aimed to develop and validate a model based on the New Zealand 
patient data to estimate the probability of EGFR mutations in patients with non-squamous NSCLC. To do so, we further expanded our population-based retrospective cohort study to include a total of 3556 patients from northern New Zealand diagnosed with non-squamous NSCLC up until July 2017. Our analysis confirmed associations of EGFR mutations with gender, ethnicity and smoking status in a New Zealand context, and allowed us to develop and validate a statistical model for estimating the EGFR mutation probability, based on readily available demographic factors, in our local patient population.

\section{Methods}

\section{Patient data}

This population-based retrospective cohort study involved all patients who were diagnosed with non-squamous NSCLC and resident in northern New Zealand between 1 February 2010 and 31 July 2017. Patients were identified from the New Zealand Cancer Registry (NZCR), a wellestablished legally mandated population-based cancer registry that registers all primary cancers (excluding squamous and basal cell skin cancers) [35]. Following information was extracted: age, sex, ethnicity, District Health Board (DHB) region, date of diagnosis, morphology, site and disease extent. The data were linked to individual patient medical records (to obtain smoking data) and laboratory reports from TestSafe (to obtain EGFR mutation testing results). TestSafe is a clinical information sharing service, which compiles the laboratory and radiology reports from DHB facilities, community laboratories, and pharmacists [36]. EGFR mutations were tested by the Roche Cobas ${ }^{\oplus}$ real-time PCR that detects 41 variant sequences in the tyrosine kinase domain (exons 18-21) of the EGFR gene [37] or Agena MassARRAY OncoFOCUS ${ }^{\text {ma }}$ [38] test that detects 128 EGFR gene mutations and 63 $K R A S, N R A S$ and $B R A F$ gene mutations, which we previously validated [21]. The positive EGFR mutation in this study refers to EGFR-TKI-sensitive mutations (i.e. exon 19 LREA deletion, L858R, G719X, S768I, L861Q, E709A and R776C) detected at diagnosis prior to EGFR-TKI therapy. Patients with EGFR mutations insensitive to gefitinib or erlotinib (exon 20 insertions, exon 20 T790M alone or those detected together with another sensitive mutation at diagnosis) were categorised as EGFR negative $[39,40]$.

\section{Data analysis}

The data analysis was based on 1794 eligible (1665 tested, and 129 non-tested EGFR-TKI-treated) patients with complete data, derived from the total of 3815 patients (Fig. 1). The 1665 tested patients were divided into a development group $(n=1176)$, diagnosed from 1 Mar 2014 to 31 July 2017, which was used for model development and internal validation; and a validation group ( $n=489$ ), diagnosed from 1 Feb 2010 to 28 Feb 2014, which was used for external validation. A separate group of the 129 patients, who were not tested for the EGFR mutation but treated with EGFR-TKIs, was used to evaluate the model's applicability. All analyses were performed using Stata v15. The model was then graphically illustrated in a nomogram by using the "regplot" command in $\mathrm{R}$ [41].

\section{Model development}

The model was developed in the development group of 1176 patients. First, single variable analyses were performed using age at diagnosis, sex, ethnicity, smoking status, disease extent and histology variables to identify the predictors of EGFR mutations. A $p$-value of $<0.05$ was considered statistically significant. Then, a multivariable logistic regression analysis was used to estimate the probabilities of EGFR mutations. Age at diagnosis and extent of the disease were excluded from the model as they were statistically non-significant in multivariable regression. The histology variable, although significant, was omitted from the model since our patient sample included few patients with histological types other than adenocarcinoma; and the area under the curve (AUC) improved little by adding histology to the model. Thus, sex, ethnicity and smoking status were included in the final model. The resultant model was presented using a nomogram.

\section{Model validation}

The model was internally validated in the development group of 1176 patients and externally validated in the validation group of 489 patients [42], in terms of calibration and discrimination.

Calibration assesses the fit between predicted and observed mutation prevalence in groups of patients. To evaluate the model's calibration, patients were divided into 5 groups created by the ranks of their predicted probabilities. Note that the numbers of observations in the groups were not equal as there were ties in predicted probabilities, that is, the same values were clustered into one group. Hosmer-Lemeshow's goodness-of-fit tests were performed, and calibration was considered poor if the $p$-value was less than 0.05 .

Discrimination assesses the model's ability to distinguish between patients with a mutation and those without [42]. To evaluate the model's discrimination, a Receiver Operating Characteristic (ROC) curve was plotted with the values of sensitivity (true positive rates) and 1-specifity (false positive rates) at consecutive cut points between 0 and 1 of the predicted probabilities. The area under the ROC curve (AUC) was used to determine the model's performance in distinguishing between mutation-positive and -negative groups. An AUC of 1 represents perfect discrimination 


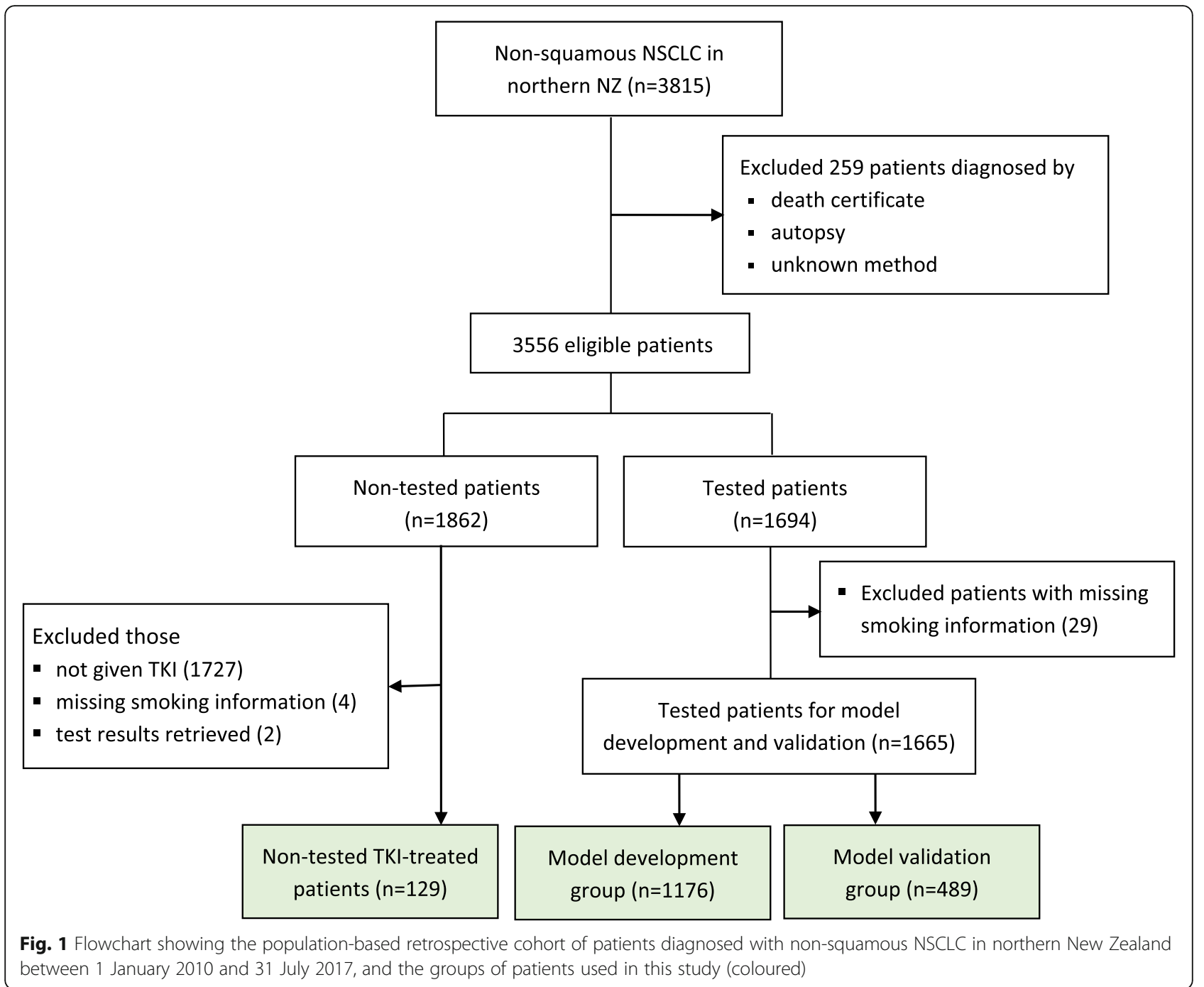

whereas 0.5 shows no discrimination beyond chance. The sensitivities and specificities were plotted against various predicted probability cut points, with the details reported for the cut points of 0.2 and 0.6 .

\section{Performance in untested patients}

The applicability of the model was assessed in a group of 129 patients who were not tested for EGFR mutations, but were treated with EGFR-TKIs. The validity of the model is shown by differences in treatment outcomes in terms of predicted mutation status, in the absence of tissue testing. Patients were categorised into three mutation probability groups using the cut points of 0.2 and 0.6. Overall survival and proportions remaining on EGFR-TKI over time up to 3 years were then compared using Kaplan-Meier estimates and log-rank tests. Overall survival was measured from the start of EGFR-TKI to the date of death, and surviving patients were censored on 31 May 2018. Time on EGFR-TKI treatment was measured from the start date to the stop date of the treatment or date of death.

\section{Results}

Patient characteristics

A total of 3815 potentially eligible patients from northern New Zealand were identified who had been diagnosed with non-squamous NSCLC between 1 January 2010 and 31 July 2017 (Fig. 1). Patients whose diagnoses were made by death certificate, autopsy or an unknown basis were excluded $(n=259)$. Of 3556 eligible patients, 1862 patients were not tested for EGFR mutations including 129 patients who were treated with EGFR-TKIs. Of the 1694 patients who were tested for EGFR mutation(s), 29 were excluded due to missing smoking information. Of the remaining 1665 tested patients, 342 (20.5\%) were mutation-positive (21\% in the development group and $18 \%$ in the validation group) (Table 1). Of 339 EGFR mutation-positive patients, 164 (48.4\%) had 
Table 1 Patient characteristics of the development, validation and non-tested EGFR-TKI-treated groups

\begin{tabular}{|c|c|c|c|c|c|c|c|c|}
\hline & \multicolumn{2}{|c|}{ Development group } & \multicolumn{2}{|c|}{ Validation group } & \multicolumn{2}{|l|}{ Total } & \multicolumn{2}{|c|}{ Non-tested EGFR-TKI treated group } \\
\hline & $\mathrm{N}$ & $\%$ & $\mathrm{~N}$ & $\%$ & $\mathrm{~N}$ & $\%$ & $\mathrm{~N}$ & $\%$ \\
\hline Total & 1176 & 100 & 489 & 100 & 1665 & 100 & 129 & 100 \\
\hline \multicolumn{9}{|l|}{ Mutation status } \\
\hline No & 927 & 78.8 & 399 & 81.6 & 1326 & 79.6 & - & - \\
\hline Yes & 249 & 21.2 & 90 & 18.4 & 339 & 20.4 & & \\
\hline \multicolumn{9}{|l|}{ Mutation types } \\
\hline $\begin{array}{l}\text { Exon } 19 \text { deletion } \\
\text { Exon } 21 \mathrm{~L} 858 \mathrm{R} \\
\text { Exon } 18 \mathrm{G} 719 \mathrm{X} \\
\text { Exon } 18 \mathrm{G} 719 \mathrm{X}+\text { Exon } 20 \mathrm{~S} 768 \mathrm{I} \\
\text { Exon } 20 \mathrm{~S} 768 \mathrm{I} \\
\text { Exon } 20 \mathrm{~S} 768 \mathrm{I}+\text { Exon } 21 \mathrm{~L} 858 \mathrm{R} \\
\text { Exon } 18 \mathrm{G} 719 \mathrm{X}+\text { Exon } 18 \mathrm{E} 709 \mathrm{~A} \\
\text { Exon } 21 \mathrm{~L} 861 \mathrm{Q} \\
\text { Exon } 20 \mathrm{R} 776 \mathrm{C}+\text { Exon } 21 \mathrm{~L} 858 \mathrm{R} \\
\text { Exon } 18 \mathrm{G} 719 \mathrm{X}+\text { Exon } 21 \mathrm{~L} 861 \mathrm{Q} \\
\text { Exon } 19 \text { deletion + Exon } 20 \mathrm{~S} 768 \mathrm{l}\end{array}$ & $\begin{array}{l}117 \\
102 \\
12 \\
7 \\
2 \\
3 \\
2 \\
1 \\
1 \\
1 \\
1\end{array}$ & $\begin{array}{l}47.0 \\
41.0 \\
4.8 \\
2.8 \\
0.8 \\
1.2 \\
0.8 \\
0.4 \\
0.4 \\
0.4 \\
0.4\end{array}$ & $\begin{array}{l}47 \\
35 \\
3 \\
3 \\
1 \\
0 \\
0 \\
1 \\
0 \\
0 \\
0\end{array}$ & $\begin{array}{l}52.2 \\
38.9 \\
3.3 \\
3.3 \\
1.1 \\
0 \\
0 \\
1.1 \\
0 \\
0 \\
0\end{array}$ & $\begin{array}{l}164 \\
137 \\
15 \\
10 \\
3 \\
3 \\
2 \\
2 \\
1 \\
1 \\
1\end{array}$ & $\begin{array}{l}48.4 \\
40.4 \\
4.4 \\
3.0 \\
0.9 \\
0.9 \\
0.6 \\
0.6 \\
0.3 \\
0.3 \\
0.3\end{array}$ & - & - \\
\hline \multicolumn{9}{|l|}{ Age at diagnosis } \\
\hline$<50 \mathrm{yr}$ & 74 & 6.3 & 40 & 8.2 & 114 & 6.9 & 15 & 11.6 \\
\hline $50-59 \mathrm{yr}$ & 186 & 15.8 & 92 & 18.8 & 278 & 16.7 & 36 & 27.9 \\
\hline $60-69 \mathrm{yr}$ & 361 & 30.7 & 167 & 34.2 & 528 & 31.7 & 46 & 35.7 \\
\hline 70-79yr & 412 & 35.0 & 144 & 29.5 & 556 & 33.4 & 29 & 22.5 \\
\hline$>=80 \mathrm{yr}$ & 143 & 12.2 & 46 & 9.4 & 189 & 11.4 & 3 & 2.3 \\
\hline \multicolumn{9}{|l|}{ Sex } \\
\hline Male & 513 & 43.6 & 218 & 44.6 & 731 & 43.9 & 54 & 41.9 \\
\hline Female & 663 & 56.4 & 271 & 55.4 & 934 & 56.1 & 75 & 58.1 \\
\hline \multicolumn{9}{|l|}{ Ethnicity } \\
\hline NZ European & 682 & 58.0 & 293 & 59.9 & 975 & 58.6 & 75 & 58.1 \\
\hline NZ Maori & 175 & 14.9 & 68 & 13.9 & 243 & 14.6 & 20 & 15.5 \\
\hline Pacific & 127 & 10.8 & 53 & 10.8 & 180 & 10.8 & 13 & 10.1 \\
\hline Asian & 177 & 15.1 & 68 & 13.9 & 245 & 14.7 & 20 & 15.5 \\
\hline Other \& Unknown & 15 & 1.3 & 7 & 1.4 & 22 & 1.3 & 1 & 0.8 \\
\hline \multicolumn{9}{|l|}{ Smoking } \\
\hline Current smoker & 264 & 22.5 & 112 & 22.9 & 376 & 22.6 & 29 & 22.5 \\
\hline Non-smoker & 308 & 26.2 & 116 & 23.7 & 424 & 25.5 & 41 & 31.8 \\
\hline Ex-smoker & 604 & 51.4 & 261 & 53.4 & 865 & 52.0 & 59 & 45.7 \\
\hline \multicolumn{9}{|l|}{ Extent } \\
\hline Localised & 130 & 11.1 & 37 & 7.6 & 167 & 10.0 & 2 & 1.6 \\
\hline Adjacent or regional & 266 & 22.6 & 120 & 24.5 & 386 & 23.2 & 22 & 17.1 \\
\hline Distant & 561 & 47.7 & 232 & 47.4 & 793 & 47.6 & 80 & 62.0 \\
\hline Unknown & 219 & 18.6 & 100 & 20.5 & 319 & 19.2 & 25 & 19.4 \\
\hline \multicolumn{9}{|l|}{ Histology } \\
\hline Adenocarinoma & 1024 & 87.1 & 433 & 88.6 & 1457 & 87.5 & 105 & 81.4 \\
\hline Other & 152 & 12.9 & 56 & 11.5 & 208 & 12.5 & 24 & 18.6 \\
\hline
\end{tabular}

exon 19 deletions, 137 (40.4\%) had L858R point mutations and $38(11.3 \%)$ had other mutations (Table 1). Thirty-seven patients (exon 20 insertions, $n=33$; exon
20 T790M alone, with exon 21 L858R or exon 19 deletion, $n=4)$ were categorised as EGFR mutation-negative. The distribution of demographic, clinical and pathological 
factors was similar between the development, validation and non-tested EGFR-TKI-treated groups. A majority of patients were between 50 and 79 years old, predominantly female, NZ European, ex-smokers, and had distant spread of the disease at diagnosis. Most tumours were adenocarcinoma (Table 1).

\section{The predictive model for estimating the probability of EGFR mutation}

In single factor analyses, sex, ethnicity, smoking status, disease extent and histology were significantly associated with the EGFR gene mutation status (Table 2). In the final multivariable model including sex, ethnicity and smoking status, females (compared to males; $\mathrm{OR}=1.5$, 95\% CI 1.1-2.1), Asian and Pacific patients (compared to European patients; $\mathrm{OR}=2.8$ and 1.6 , respectively) and non-smokers and ex-smokers (compared to current smokers; $\mathrm{OR}=6.7$ and 2, respectively) were more likely to harbour EGFR mutation(s) (Table 2). The nomogram illustrates the predictive model with the estimated EGFR mutation probabilities (Fig. 2).

\section{Calibration of observed and predicted probabilities}

In both development and validation groups, the predicted probabilities ranged from 4 to $62 \%$ (Table 3, Fig. 3). The mean predicted probabilities fell within the 95\% confidence intervals of observed probabilities for all groups. The Hosmer-Lemeshow test showed adequate goodness-of-fit of the model both in the development group $(p=0.08)$, and in the validation group $(p=0.21)$.

Table 2 Single and multi-variable analysis

\begin{tabular}{|c|c|c|c|c|c|c|}
\hline & \multicolumn{3}{|c|}{ Single factor analysis } & \multicolumn{3}{|c|}{ Multivariable analysis } \\
\hline & \multicolumn{2}{|c|}{ Mutation positive } & \multirow[t]{2}{*}{$p$-value } & \multirow[t]{2}{*}{ OR } & \multirow[t]{2}{*}{$(95 \%$ Cl) } & \multirow[t]{2}{*}{$p$-value } \\
\hline & N & $\%$ & & & & \\
\hline Total & 249 & 21.17 & & & & \\
\hline Age at diagnosis & & & 0.063 & & & \\
\hline$<50$ year & 21 & 28.38 & & & & \\
\hline 50-59 year & 37 & 19.89 & & & & \\
\hline 60-69 year & 60 & 16.62 & & & & \\
\hline 70-79 year & 97 & 23.54 & & & & \\
\hline$>=80$ year & 34 & 23.78 & & & & \\
\hline Sex & & & $<0.001$ & & & \\
\hline Male & 77 & 15.01 & & 1 & & \\
\hline Female & 172 & 25.94 & & 1.5 & $(1.1-2.1)$ & 0.014 \\
\hline Ethnicity & & & $<0.001$ & & & \\
\hline NZ European & 105 & 15.4 & & 1 & & \\
\hline NZ Maori & 16 & 9.14 & & 0.7 & $(0.4-1.2)$ & 0.201 \\
\hline Pacific & 35 & 27.56 & & 1.6 & $(1.0-2.6)$ & 0.052 \\
\hline Asian & 87 & 49.15 & & 2.8 & $(1.8-4.2)$ & $<0.001$ \\
\hline Other \& Unknown & 6 & 40 & & 2.5 & $(0.8-7.5)$ & 0.118 \\
\hline Smoking status & & & $<0.001$ & & & \\
\hline Current smoker & 19 & 7.2 & & 1 & & \\
\hline Ex-smoker & 85 & 14.07 & & 2 & $(1.2-3.5)$ & 0.008 \\
\hline Non-smoker & 145 & 47.08 & & 6.7 & $(3.9-11.7)$ & $<0.001$ \\
\hline Extent & & & 0.005 & - & & \\
\hline Localised & 42 & 32.31 & & & & \\
\hline Adjacent or regional & 50 & 18.8 & & & & \\
\hline Distant spread & 106 & 18.89 & & & & \\
\hline Unknown & 51 & 23.29 & & & & \\
\hline Histology & & & $<0.001$ & - & & \\
\hline Adenocarcinoma & 238 & 23.24 & & & & \\
\hline Other & 11 & 7.24 & & & & \\
\hline
\end{tabular}




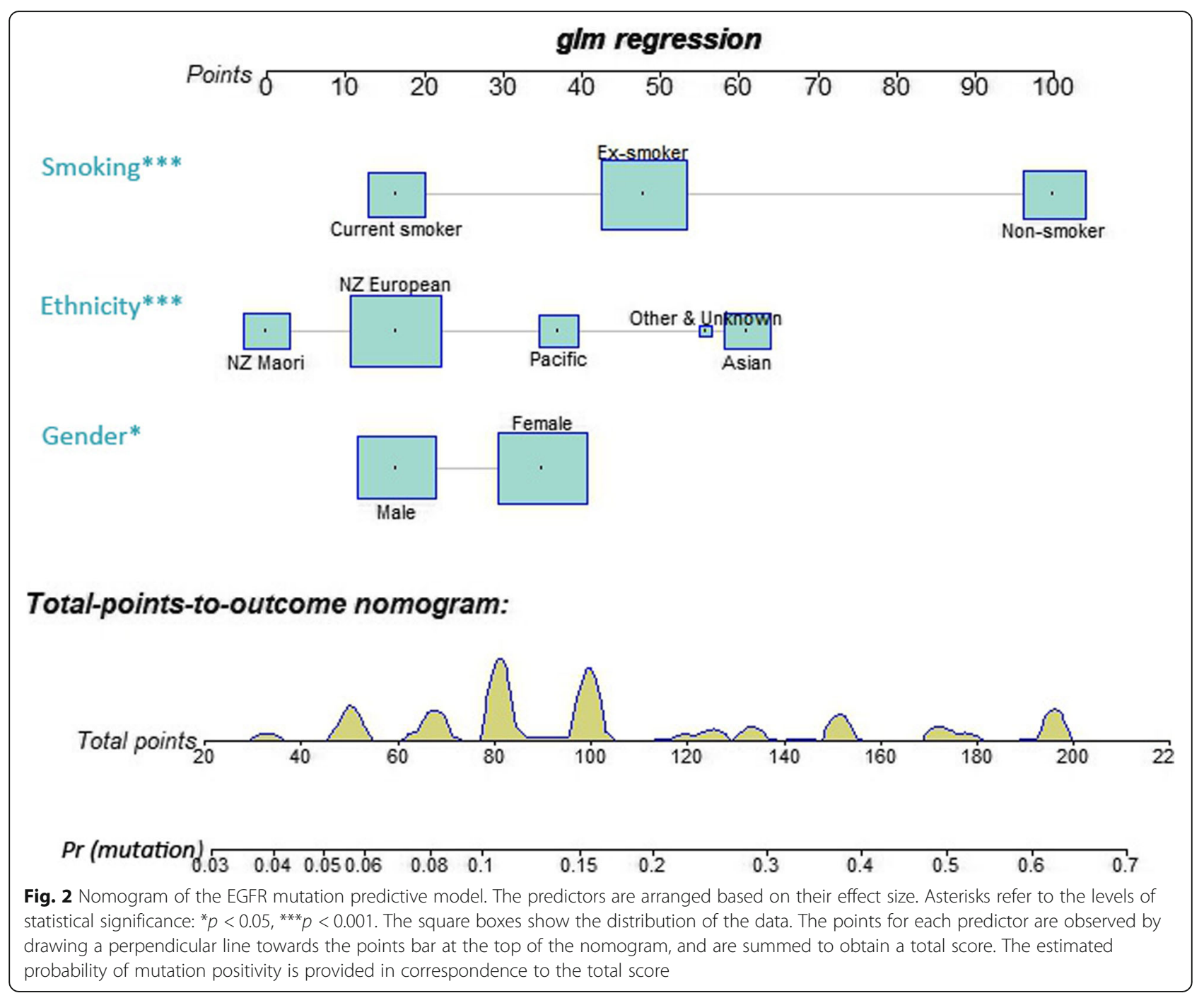

Table 3 Calibration assessment of the EGFR mutation predictive model

\begin{tabular}{|c|c|c|c|c|c|c|c|}
\hline \multirow{2}{*}{$\begin{array}{l}\text { Group } \\
a\end{array}$} & \multirow[t]{2}{*}{$\mathrm{N}$} & \multicolumn{3}{|c|}{ Predicted EGFR mutation } & \multicolumn{3}{|c|}{ Observed EGFR mutation } \\
\hline & & Number & Mean & (min-max) & Number & Proportion & $(95 \% \mathrm{Cl})$ \\
\hline \multicolumn{8}{|c|}{ Development group } \\
\hline 1 & 254 & 17 & 0.07 & $(0.04-0.08)$ & 18 & 0.07 & $(0.04-0.11)$ \\
\hline 2 & 228 & 24 & 0.11 & $(0.09-0.11)$ & 14 & 0.06 & $(0.04-0.10)$ \\
\hline 3 & 282 & 41 & 0.14 & $(0.11-0.15)$ & 41 & 0.15 & $(0.11-0.19)$ \\
\hline 4 & 234 & 67 & 0.28 & $(0.16-0.38)$ & 80 & 0.34 & $(0.28-0.40)$ \\
\hline 5 & 178 & 101 & 0.57 & $(0.39-0.62)$ & 96 & 0.54 & $(0.47-0.61)$ \\
\hline \multicolumn{8}{|c|}{ Validation group } \\
\hline 1 & 100 & 7 & 0.07 & $(0.04-0.08)$ & 7 & 0.07 & $(0.03-0.14)$ \\
\hline 2 & 100 & 10 & 0.10 & $(0.09-0.11)$ & 9 & 0.09 & $(0.05-0.16)$ \\
\hline 3 & 133 & 20 & 0.15 & $(0.11-0.15)$ & 15 & 0.11 & $(0.07-0.18)$ \\
\hline 4 & 59 & 14 & 0.23 & $(0.16-0.29)$ & 13 & 0.22 & $(0.13-0.34)$ \\
\hline 5 & 97 & 48 & 0.50 & $(0.31-0.62)$ & 46 & 0.47 & $(0.38-0.57)$ \\
\hline
\end{tabular}

${ }^{a}$ The five groups were created by the ranks of the predicted probabilities 
(a)

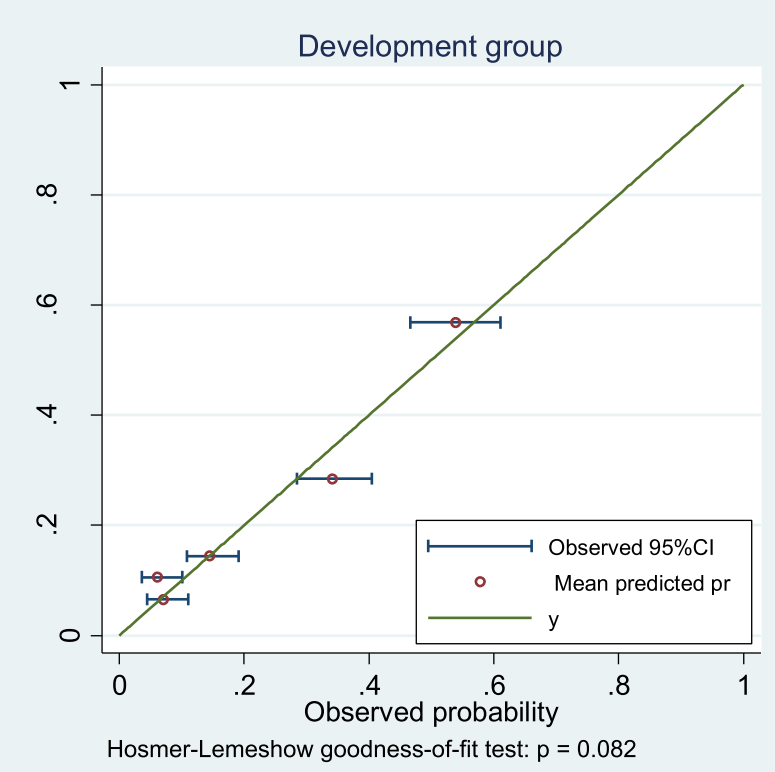

(b)

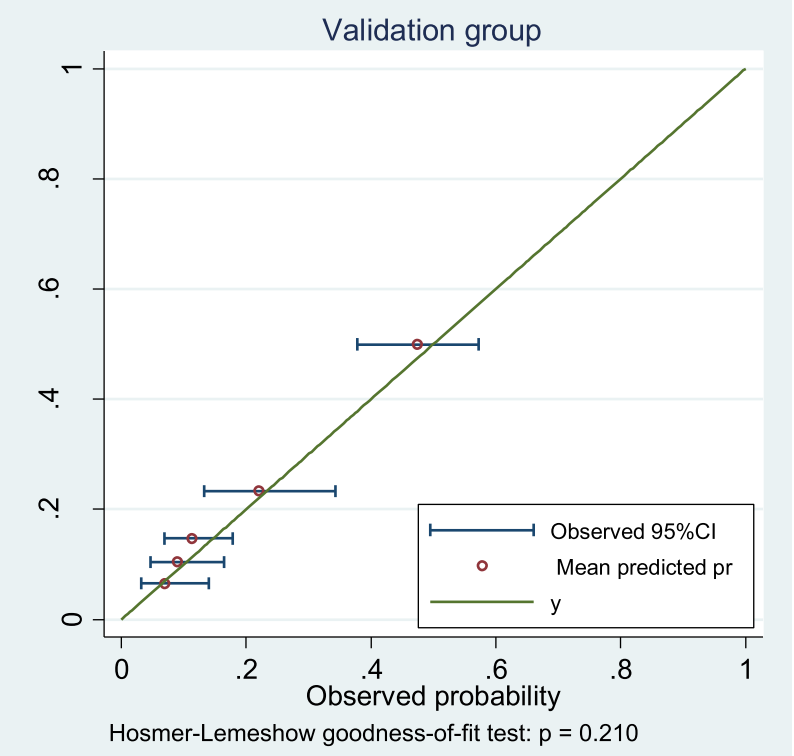

Fig. 3 Calibration plots. Assessment of the model's internal validity using the development group (a), and external validity using the validation group (b): the mean predicted EGFR mutation probabilities plotted against the observed mutation probabilities with their $95 \% \mathrm{Cl}$, shown in five groups created by the ranks of the predicted probabilities. Hosmer-Lemeshow test compares the observed and predicted probabilities: a $p$-value of $>0.05$ indicates good calibration

\section{Discrimination between mutation positive and negative patients}

The Receiver Operating Characteristic (ROC) curves show the probability curves with corresponding true positive rates and false positive rates (Fig. 4). The model's AUC was similar in the development group (0.78) and the validation group (0.75). The maximum separation was at probability cut point of 0.2 , achieving a negative predictive value (NPV) of 90\% for the development group and 91\% for the validation group; a positive predicted value (PPV) of 46 and 41\%; and an Informedness index of 0.46 and 0.43 , respectively (Table 4). An NPV of $90 \%$ means that $90 \%$ of patients classified by the model as not having EGFR mutations at this cut point, in actuality did not have an EGFR mutation. A PPV of $46 \%$ means that $46 \%$ of patients classified by the model as having EGFR mutation, in actuality had an EGFR mutation. An Informedness index of 0.46 means an appropriate use of information [43].

Treatment outcomes by predicted mutation probability in a non-tested EGFR-TKI-treated group

This group involves 129 patients treated with EGFRTKIs, who were not tested for EGFR mutations. Figure 5 shows that outcomes are related to the estimated probability of a mutation as given by the model. Using the 0.2 and 0.6 cut points, the median overall survival times from starting EGFR-TKI treatment were 4 months in < 0.2 group, 5.5 months in $0.2-0.6$ group, and 18.3 months in $>0.6$ group $(p=0.024)$. The median times on EGFRTKI treatment from the start date were 2 months, 4.2 months, and 14 months, respectively $(p<0.001)$.

\section{Discussion}

We developed a model to estimate the probability of EGFR mutation based on a population-based series of 1176 non-squamous NSCLC patients in northern New Zealand. Our model included three predictors that were significantly associated with the EGFR mutation status in the multivariable analysis: sex, ethnicity and smoking status. The female sex, Asian ethnicity and being a nonsmoker were highly associated with higher prevalence of EGFR mutation, as observed in previous studies [1, 2].

We presented the fitted model using a nomogram, which is an increasingly used format for clinical prediction models for its ability to provide exact predictions [44]. We validated the model using established performance measures [44]. The model showed good calibration with the mean predicted probabilities being within the $95 \%$ limits of the observed values in all the groups for both development and validation. The goodness-of-fit was slightly better in the validation group than the development group. The AUCs of 0.78 in the development group and 0.75 in the validation group inferred that our model performed reasonably well. Further, in a retrospective group of NSCLC patients treated with EGFR-TKIs without EGFR mutation testing, patients with higher $E G F R$ mutation probabilities estimated from 

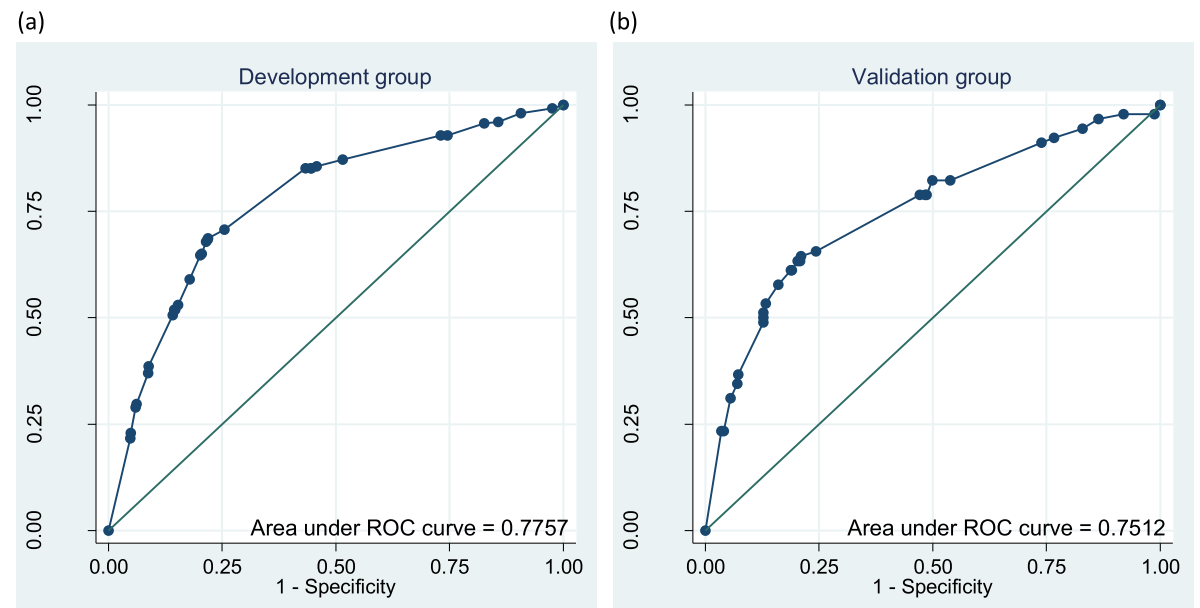

(c)

(d)
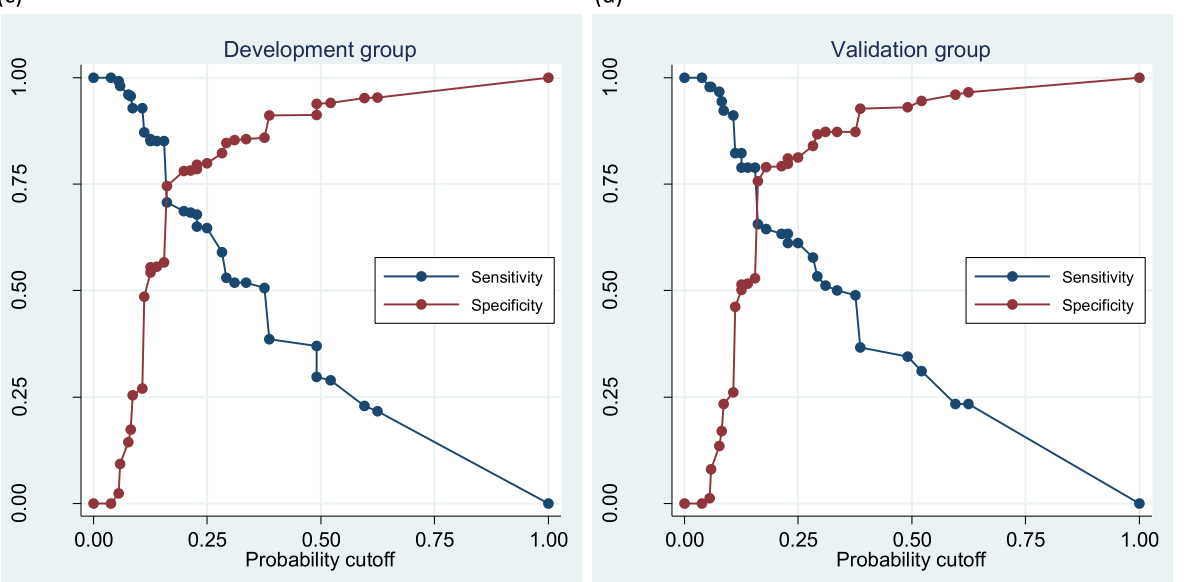

Fig. 4 Sensitivity and specificity reports. ROC curves using the development group (a), and the validation group (b); Detailed sensitivity \& specificity report for individual cut-points using the development group (c), and the validation group (d)

the model had significantly longer overall survival and longer duration of EGFR-TKI treatment than those with lower EGFR mutation probabilities.

We considered possible limitations of our model. The patients included in our model were of necessity those

Table 4 Detailed sensitivity and specificity report for EGFR mutation predicted probability cut-points of 0.2 and 0.6

\begin{tabular}{llllll}
\hline & \multicolumn{2}{l}{ Development group } & & \multicolumn{2}{c}{ Validation group } \\
\cline { 2 - 3 } & 0.2 & 0.6 & & 0.2 & 0.6 \\
\hline Sensitivity & $68.27 \%$ & $21.69 \%$ & & $63.33 \%$ & $23.33 \%$ \\
Specificity & $78.21 \%$ & $95.25 \%$ & & $79.20 \%$ & $96.49 \%$ \\
Positive predictive value & $45.70 \%$ & $55.10 \%$ & & $40.71 \%$ & $60.00 \%$ \\
Negative predictive value & $90.17 \%$ & $81.91 \%$ & & $90.54 \%$ & $84.80 \%$ \\
Informedness index ${ }^{\text {a }}$ & 0.46 & 0.17 & & 0.43 & 0.2
\end{tabular}

${ }^{a}$ Informedness index is calculated as sensitivity+specificity-1. Interpretation: 0 means the test is useless, 1 means the test is perfect, and a value of $>0$ means an appropriate use of information [Reference: Youden WJ. Index for rating diagnostic tests. Cancer. 1950;3(1):32-5] who had been tested for the EGFR gene mutation. Our earlier work showed that EGFR mutation testing increased from $3.7 \%$ of all patients in 2010 to $64.6 \%$ in 2014 in this population-based retrospective cohort [20]. In parallel, recorded EGFR mutation rates decreased from $43.8 \%$ in 2010 to $16.8 \%$ in 2014 , reflecting decreases in selective testing [22]. Taking into account this variation, we assessed the external validity of the model in the independent earlier period dataset, and the results were similar to those in the development group. The EGFR mutation prevalence in this study is within the range of the largest systematic review, being $47 \%$ in Asia-Pacific region and $12 \%$ in Australia [2]. The predictive model does not provide information about what particular EGFR mutation may be present, which could be important for clinical decision-making.

Models with combined clinical factors and imaging features may improve performance in predicting EGFR mutation status [26, 28, 33, 45-48]. However, extracting 


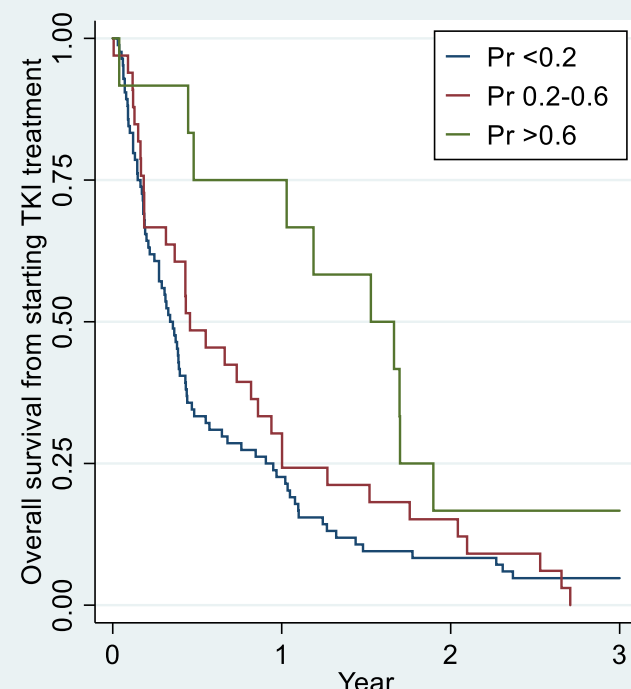

Number at risk

$\begin{array}{llcll}\operatorname{Pr}<0.2 & 84 & 19 & 7 & 4 \\ \operatorname{Pr} 0.2-0.6 & 33 & 10 & 5 & 0 \\ \operatorname{Pr}>0.6 & 12 & 9 & 2 & 2 \\ & \text { Log-rank test: } \mathrm{p}=0.0242 & & \end{array}$

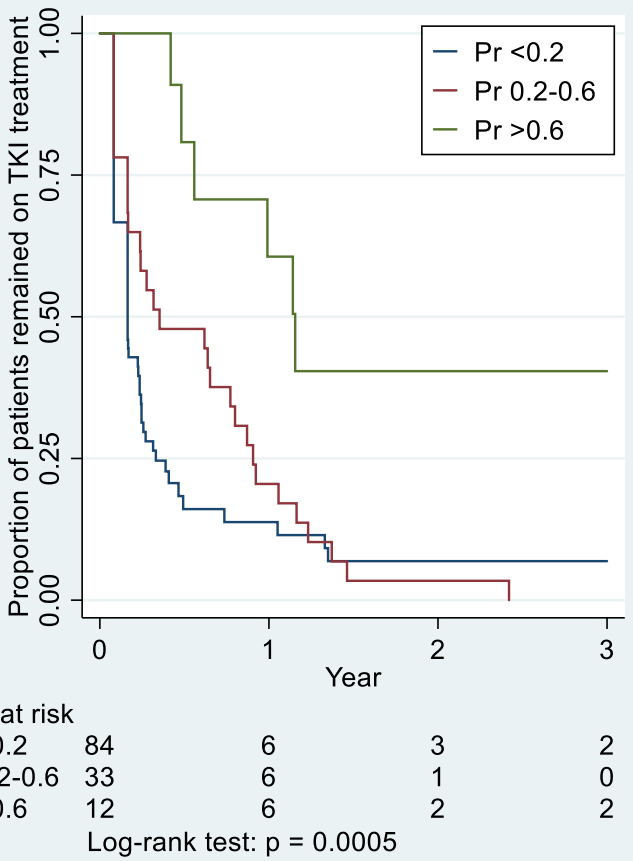

Fig. 5 Survival outcomes from EGFR-TKI treatment in a group of untested NSCLC patients $(n=129)$ by estimated EGFR mutation probability (pr < $0.2,0.2-0.6$, and $>0.6$ )

radiological features from clinical or radiological reports is complex unless a particular recording system is added to routine records for this purpose. For instance, in Zhang et al. [28] study, as many as 485 CT features were used for their Rad_signature scoring system, which is unlikely to be feasible in our setting. Thus, we developed the current model with the important available clinical factors only.

Our model includes New Zealand specific ethnicities including Māori and Pacific people. Māori and Pacific people have a higher incidence of lung cancer and poorer survival, compared to the New Zealand European population [49]. But, the testing rate was particularly low in Māori patients compared to other ethnic groups [22]. Our model may be helpful in addressing ethnic disparity in lung cancer patients in New Zealand. Moreover, a combined nomogram for both Asian and non-Asian populations showed unsatisfactory accuracy in the study of Gevaert et al. [26]. It claimed that Asian patients had substantially different distributions of the predictors. Thus, developing ethnic specific models may be relevant in future research.

We categorised the patients into three groups based on the probability of EGFR mutation positivity: low $(<0.2)$, medium (0.2-0.6) and high (>0.6) probability groups. We then compared the duration of benefit and the overall survival from the start of EGFR-TKI treatment between the three probability subgroups in a group who had been treated with EGFR-TKIs second-line, without a tissue test result for mutations. The outcomes were significantly more favourable in the higher probability group than the lower probability group with outcomes of the medium probability group being intermediate of the other two. These findings demonstrate that our model has the potential to predict mutation status and can differentiate between untested patients who have good outcomes from EGFR-TKI treatment and those who will have poor treatment outcomes. Thus, when testing is not possible, those in the high probability group could be considered for EGFR-TKI treatment. Conversely, those in the low probability group should not receive an EGFR-TKI. These findings are consistent with published randomised controlled clinical trials showing the relative benefits of EGFR-TKIs versus chemotherapy for untested NSCLC patients to critically depend upon the proportion of patients demonstrated to have EGFR mutations by post hoc mutation testing [6, 7, 50-52].

EGFR mutation status can also be estimated by liquid biopsy to detect circulating DNA in plasma. The sensitivity of this, compared with tissue biopsy, varies considerably in different series and with the methods used, but may be about $85 \%$ in advanced disease, but lower in less advanced cases [24, 25]. However, these methods are expensive and not readily available in New Zealand. False negative results are of concern. While our EGFR mutation predictive model cannot replace molecular 
testing, in patients for whom tissue biopsy is difficult, it could be used in conjunction with liquid biopsy, giving further attention to patients with a high estimated probability, but a negative liquid biopsy result, suggesting a false negative.

Our study is moderate in size, and applies to a multiethnic population in New Zealand, so application to other populations requires further studies. Our model used only three factors, and other factors such as radiological appearances, blood markers such as CEA [53], or more precise classification of smoking history, may yield improved models.

\section{Conclusion}

We have developed and validated a model for estimating the probability of EGFR mutations in non-squamous NSCLC patients based on routinely collected factors. This model may be useful for supporting clinical decisions for patients in whom mutation testing is difficult or for use alongside mutation testing.

\section{Acknowledgements}

Not applicable.

\section{Authors' contributions}

PSA: conceptualization-Equal, Formal analysis-Lead, Methodology-Equal, Validation-Equal, Writing-original draft-Lead, Writing-review \& editing-Equal. STT: Formal analysis-Supporting, Methodology-Supporting, Supervision-Equal, Writing-review \& editing-Equal. MJM: Conceptualization-Equal, Funding acquisition-Lead, Methodology-Equal, Supervision-Equal, Writing-review \& editing-Equal. PK: Data curation-Lead. AC: Formal analysis-Supporting. JME: Conceptualization-Equal, Methodology-Equal, Supervision-Equal, Writingreview \& editing-Equal. All authors have read and approved the manuscript.

\section{Author's information}

Phyu Sin Aye, PhD candidate | Research assistant, Epidemiology and Biostatistics, University of Auckland, New Zealand.

Sandar Tin Tin, Senior research fellow, Epidemiology and Biostatistics, University of Auckland, New Zealand.

Mark James McKeage, Professor - Medical, Pharmacology and Clinical Pharmacology | Auckland Cancer Society Research Centre, University of Auckland, New Zealand.

Prashannata Khwaounjoo, Clinical trials manager, Pharmacology and Clinical Pharmacology, University of Auckland, New Zealand.

Alana Cavadino, Biostatistician, Epidemiology and Biostatistics, University of Auckland, New Zealand.

J Mark Elwood, Professor - Cancer Epidemiology, Epidemiology and Biostatistics, University of Auckland, New Zealand.

\section{Funding}

This research was funded by the Health Research Council, New Zealand (funding projects 13-981 and 15-087). Phyu Aye's PhD has been funded by The University of Auckland Doctoral Scholarship.

The funders had no role in research design, data collection, data analysis, or preparation of the manuscript for publication.

\section{Availability of data and materials}

The data that support the findings of this study are available from New Zealand Cancer Registry and TestSafe information sharing database but restrictions apply to the availability of these data, and so are not publicly available. Data are however available from the authors upon reasonable request and with permission of corresponding data owners.

\section{Ethics approval and consent to participate}

Our study used secondary data routinely recorded by the New Zealand Cancer Registry and TestSafe; as such, consent to participate was not applicable.

The ethical approval for use of data for research purpose was obtained from the Northern B Health and Disability Ethics Committee, New Zealand (reference: 13/NTB/165/AM02).

\section{Consent for publication}

Not applicable.

\section{Competing interests}

The authors declare that they have no competing interests.

\section{Author details}

${ }^{1}$ Epidemiology and Biostatistics, University of Auckland, B507, 22-30 Park Ave, Grafton, Auckland 1072, New Zealand. ${ }^{2}$ Pharmacology and Clinical Pharmacology, University of Auckland, Auckland, New Zealand. ${ }^{3}$ Auckland Cancer Society Research Centre, University of Auckland, Auckland, New Zealand.

Received: 20 October 2019 Accepted: 9 July 2020

Published online: 14 July 2020

\section{References}

1. Zhang Y-L, Yuan J-Q, Wang K-F, Fu X-H, Han X-R, Threapleton D, et al. The prevalence of EGFR mutation in patients with non-small cell lung cancer: a systematic review and meta-analysis. Oncotarget. 2016;7(48):78985-93.

2. Midha A, Dearden S, McCormack R. EGFR mutation incidence in non-smallcell lung cancer of adenocarcinoma histology: a systematic review and global map by ethnicity (mutMapll). Am J Cancer Res. 2015;5(9):2892-911.

3. Pao W, Chmielecki J. Rational, biologically based treatment of EGFR-mutant non-small-cell lung cancer. Nat Rev Cancer. 2010;10(11):760-74.

4. Shepherd FA, Pereira JR, Ciuleanu T, Tan EH, Hirsh V, Thongprasert S, et al. Erlotinib in previously treated non-small-cell lung cancer. N Engl J Med. 2005;353(2):123-32.

5. Lynch J, Bell DW, Sordella R, Gurubhagavatula S, Okimoto RA, Brannigan BW, et al. Activating mutations in the epidermal growth factor receptor underlying responsiveness of non-small-cell lung cancer to gefitinib. N Engl J Med. 2004;350(21):2129-39.

6. Han JY, Park K, Kim SW, Lee DH, Kim HY, Kim HT, et al. First-SIGNAL: first-line single-agent iressa versus gemcitabine and cisplatin trial in never-smokers with adenocarcinoma of the lung. J Clin Oncol. 2012;30(10):1122-8.

7. Mok TS, Wu Y-L, Thongprasert S, Yang C-H, Chu D-T, Saijo N, et al. Gefitinib or carboplatin-paclitaxel in pulmonary adenocarcinoma. N Engl J Med. 2009;361(10):947-57

8. Mitsudomi T, Morita S, Yatabe Y, Negoro S, Okamoto I, Tsurutani J, et al. Gefitinib versus cisplatin plus docetaxel in patients with non-small-cell lung cancer harbouring mutations of the epidermal growth factor receptor (WJTOG3405): an open label, randomised phase 3 trial. Lancet Oncol. 2010; 11(2):121-8

9. Maemondo M, Inoue A, Kobayashi K, Sugawara S, Oizumi S, Isobe H, et al. Gefitinib or chemotherapy for non-small-cell lung cancer with mutated EGFR. N Engl J Med. 2010;362(25):2380-8.

10. Zhou C, Wu Y-LL, Chen G, Feng J, Liu X-QQ, Wang C, et al. Erlotinib versus chemotherapy as first-line treatment for patients with advanced EGFR mutation-positive non-small-cell lung cancer (OPTIMAL, CTONG-0802): a multicentre, open-label, randomised, phase 3 study. Lancet Oncol. 2011; 12(8):735-42

11. Wu YL, Zhou C, Liam CK, Wu G, Liu X, Zhong Z, et al. First-line erlotinib versus gemcitabine/cisplatin in patients with advanced EGFR mutationpositive non-small-cell lung cancer: analyses from the phase III, randomized, open-label, ENSURE study. Ann Oncol. 2015;26(9):1883-9.

12. Rosell R, Carcereny E, Gervais R, Vergnenegre A, Massuti B, Felip E, et al. Erlotinib versus standard chemotherapy as first-line treatment for European patients with advanced EGFR mutation-positive non-small-cell lung cancer (EURTAC): a multicentre, open-label, randomised phase 3 trial. Lancet Oncol. 2012;13(3):239-46.

13. Lee CK, Wu YL, Ding PN, Lord SJ, Inoue A, Zhou C, et al. Impact of specific epidermal growth factor receptor (EGFR) mutations and clinical characteristics on outcomes after treatment with EGFR tyrosine kinase 
inhibitors versus chemotherapy in EGFR-mutant lung cancer: a metaanalysis. J Clin Oncol. 2015;33(17):1958-65.

14. Van Schil PE, Hellmann MD, Peters S, Guidelines E. ESMO Clinical Practice Guidelines for mNSCLC. Ann Oncol. 2019;29(suppl 4):iv192-237.

15. Lindeman NI, Cagle PT, Aisner DL, Arcila ME, Beasley MB, Bernicker EH, et al. Updated molecular testing guideline for the selection of lung Cancer patients for treatment with targeted tyrosine kinase inhibitors: guideline from the College of American Pathologists, the International Association for the Study of Lung Cancer, and the. J Mol Diagnostics. 2018;20(2):129-59.

16. Kalemkerian GP, Narula N, Kennedy EB, Biermann WA, Donington J, Leighl $N B$, et al. Molecular testing guideline for the selection of patients with lung Cancer for treatment with targeted tyrosine kinase inhibitors. J Clin Oncol. 2018;36(9):911-9.

17. Wu Y, Liu H, Shi X, Song Y. Can EGFR mutations in plasma or serum be predictive markers of non-small-cell lung cancer? A meta-analysis. Lung Cancer. 2015;88(3):246-53.

18. Thi AM, Tin Tin S, McKeage M, Elwood JM. Utilisation and Determinants of Epidermal Growth Factor Receptor Mutation Testing in Patients with Nonsmall Cell Lung Cancer in Routine Clinical Practice: A Global Systematic Review. Target Oncol. 2020;15(3):279-99. https://doi.org/10.1007/s11523-020-00718-w.

19. Martin P, Leighl NB. Review of the use of pretest probability for molecular testing in non-small cell lung cancer and overview of new mutations that may affect clinical practice. Ther Adv Med Oncol. 2017;9(6):405-14.

20. McKeage M, Elwood M, Tin Tin S, Khwaounjoo P, Aye P, Li A, et al. EGFR mutation testing of non-squamous NSCLC: impact and uptake during implementation of testing guidelines in a population-based registry cohort from northern New Zealand. Target Oncol. 2017;12(5):663-75.

21. Shepherd P, Sheath KL, Tin ST, Khwaounjoo P, Aye PS, Li A, et al. Lung cancer mutation testing: a clinical retesting study of agreement between a real-time PCR and a mass spectrometry test. Oncotarget. 2017;8(60):101437-51.

22. Tin Tin S, McKeage MJ, Khwaounjoo P, Thi AM, Elwood JM. Incomplete uptake of EGFR mutation testing and its impact on estimation of mutation prevalence in patients with non-squamous NSCLC: a population-based study in New Zealand. Cancer Epidemiol. 2018;57:24-32.

23. McKeage MJ, Tin Tin S, Khwaounjoo P, Sheath K, Dixon-Mclver A, Ng D, et al. Screening for Anaplastic Lymphoma Kinase ( ALK ) gene rearrangements in non-small cell lung cancer (NSCLC) in New Zealand. Intern Med J. 2019. https://doi.org/10.1111/imj.14435.

24. Rolfo C, Mack PC, Scagliotti GV, Baas P, Barlesi F, Bivona TG, et al. Liquid biopsy for advanced non-small cell lung Cancer (NSCLC): a statement paper from the IASLC. J Thorac Oncol. 2018;13(9):1248-68.

25. Goldman JW, Noor ZS, Remon J, Besse B, Rosenfeld N. Are liquid biopsies a surrogate for tissue EGFR testing? Ann Oncol. 2018;29(Supplement 1):i38-46.

26. Gevaert $O$, Echegaray S, Khuong A, Hoang CD, Shrager JB, Jensen KC, et al. Predictive radiogenomics modeling of EGFR mutation status in lung cancer. Sci Rep. 2017;7:41674.

27. Girard N, Sima CS, Jackman DM, Sequist LV, Chen H, Yang JC-H, et al. Nomogram to predict the presence of EGFR activating mutation in lung adenocarcinoma. Eur Respir J. 2012;39(2):366-72.

28. Zhang L, Chen B, Liu X, Song J, Fang M, Hu C, et al. Quantitative biomarkers for prediction of epidermal growth factor receptor mutation in non-small cell lung Cancer. Transl Oncol. 2018;11(1):94-101.

29. Li S, Ding C, Zhang H, Song J, Wu L. Radiomics for the prediction of EGFR mutation subtypes in non-small-cell lung Cancer. Med Phys. 2019; 46(10):4545-52.

30. Wang X, Kong C, Xu W, Yang S, Shi D, Zhang J, et al. Decoding tumor mutation burden and driver mutations in early stage lung adenocarcinoma using CT-based radiomics signature. Thorac Cancer. 2019;10(10):1904-12.

31. Yang X, Dong X, Wang J, Li W, Gu Z, Gao D, et al. Computed Tomography-Based Radiomics Signature: A Potential Indicator of Epidermal Growth Factor Receptor Mutation in Pulmonary Adenocarcinoma Appearing as a Subsolid Nodule. Oncologist. 2019; 24(11):e1156-64 theoncologist.2018-0706.

32. Jia T-Y, Xiong J-F, Li X-Y, Yu W, XU Z-Y, Cai X-W, et al. Identifying EGFR mutations in lung adenocarcinoma by noninvasive imaging using radiomics features and random forest modeling. Eur Radiol. 2019;29(9):4742-50.

33. Tu W, Sun G, Fan L, Wang Y, Xia Y, Guan Y, et al. Radiomics signature: a potential and incremental predictor for EGFR mutation status in NSCLC patients, comparison with CT morphology. Lung Cancer. 2019;132:28-35.

34. Chang H, Liu Y, Bin YW, Bin LJ, Zhang JX. Development and validation of a model to predict tyrosine kinase inhibitor-sensitive EGFR mutations of non- small cell lung cancer based on multi-institutional data. Thorac Cancer. 2018;9(12):1680-6.

35. Ministry of Health NZ. New Zealand Cancer Registry, vol. 2014; 2013.

36. CareConnect. TestSafe [Internet]. 2020 [cited 2020 Mar 28]. Available from: http://www.careconnect.co.nz/testsafe/.

37. Roche Diagnostics. The cobas ${ }^{\oplus}$ EGFR Mutation Test [Internet]. 2019 [cited 2020 Mar 13]. Available from: http://www.cobasegfrtest.com/.

38. Agena Bioscience. OncoFOCUS ${ }^{\mathrm{TM}}$ panel v3: genes and mutations. 2016.

39. Yu HA, Arcila ME, Hellmann MD, Kris MG, Ladanyi M, Riely GJ. Poor response to erlotinib in patients with tumors containing baseline EGFR T790M mutations found by routine clinical molecular testing. Ann Oncol. 2014;25:423-8.

40. Yasuda H, Kobayashi S, Costa DB. EGFR exon 20 insertion mutations in nonsmall-cell lung cancer: preclinical data and clinical implications. Lancet Oncol. 2012;13(1):e23-31.

41. Marshall R. Enhanced Regression Nomogram Plot [R package regplot version 0.2]. Comprehensive R Archive Network (CRAN); 2018.

42. Altman DG. Prognostic models: a methodological framework and review of models for breast cancer. Cancer Invest Taylor \& Francis. 2009;27(3):235-43.

43. Youden WJ. Index for rating diagnostic tests. Cancer. 1950;3(1):32-5.

44. Steyerberg EW, Vickers AJ, Cook NR, Gerds T, Gonen M, Obuchowski N, et al. Assessing the performance of prediction models: a framework for traditional and novel measures. Epidemiology. 2010;21(1):128-38.

45. Sabri A, Batool M, Xu Z, Bethune D, Abdolell M, Manos D. Predicting EGFR mutation status in lung cancer: proposal for a scoring model using imaging and demographic characteristics. Eur Radiol. 2016;26(11):4141-7.

46. Rizzo S, Petrella F, Buscarino V, De Maria F, Raimondi S, Barberis M, et al. CT Radiogenomic characterization of EGFR, K-RAS, and ALK mutations in nonsmall cell lung Cancer. Eur Radiol. 2016;26(1):32-42.

47. Hsu J-S, Huang M-S, Chen C-Y, Liu G-C, Liu T-C, Chong I-W, et al. Correlation between EGFR mutation status and computed tomography features in patients with advanced pulmonary adenocarcinoma. J Thorac Imaging. 2014;29(6):357-63.

48. Zhang H, Cai W, Wang Y, Liao M, Tian S. CT and clinical characteristics that predict risk of EGFR mutation in non-small cell lung cancer: a systematic review and meta-analysis. Int J Clin Oncol. 2019;24(6):649-59.

49. Ministry of Health. New cancer registrations and deaths 2013. Wellington: New Zealand Ministry of Health; 2016

50. Sun JM, Lee KHK, Kim SW, Lee DH, Min YJ, Yun HJ, et al. Gefitinib versus pemetrexed as second-line treatment in patients with nonsmall cell lung cancer previously treated with platinum-based chemotherapy (KCSG-LU0801): an open-label, phase 3 trial. Cancer. 2012;118(24):6234-42.

51. Gridelli C, Ciardiello F, Gallo C, Feld R, Butts C, Gebbia V, et al. First-line erlotinib followed by second-line cisplatin-gemcitabine chemotherapy in advanced non-small-cell lung cancer: the TORCH randomized trial. J Clin Oncol. 2012;30(24):3002-11.

52. Heigener DF, Deppermann KM, Pawel JV, Fischer JR, Kortsik C, Bohnet S, et al. Open, randomized, multi-center phase II study comparing efficacy and tolerability of Erlotinib vs. carboplatin/Ninorelbin in elderly patients ( $>70$ years of age) with untreated non-small cell lung cancer. Lung Cancer. 2014; 84(1):62-6.

53. Liu J, Zhao YQ, Han X, Hu XF, Wu HB, Chen LJ, et al. Correlation between pre-treatment serum carcinoembryonic antigen levels and genotypes in a large population of Chinese people with advanced lung adenocarcinoma. Intern Med J. 2019;49(5):634-43.

\section{Publisher's Note}

Springer Nature remains neutral with regard to jurisdictional claims in published maps and institutional affiliations. 